\title{
Investigation of infill wall effect on inelastic response of structures
}

\begin{abstract}
Experience of recent earthquake proved that infill wall contributes to the behaviour of structures subjected to earthquake or any vibration loads. Although the infill wall is not considered during design process, as it is not a structural element. However, the function of infill wall during vibration of building has not been investigated comprehensively. Therefore, in this study, the influence of RC infill wall on seismic performance of the RC building during earthquake excitation is evaluated. For this purpose, a four-storey building; with and without RC infill wall elements is considered and finite element model is developed to study the influence of this RC infill wall in seismic response of building. Linear static, linear dynamic, nonlinear static (push over) and nonlinear dynamic (time history) analyses were all applied to the specified model for developing the finite element model of this building. On the other hand, an experimental study was carried out to verify the influence of the RC infill wall on the $\mathrm{RC}$ frame. The results indicated that utilizing $\mathrm{RC}$ infill wall can improve the response of the framed structure effectively during earthquake occurrence. It was also observed that adding infill wall in the outside bays of the four-storey building decreased the displacement of the structural nodes both in $\mathrm{x}$ and $\mathrm{y}$ directions and decreased their rotation around they and $\mathrm{z}$ axis. In addition, addition of $\mathrm{RC}$ infill walls reduced the axial forces in the columns and beams in the whole structure. Besides, a clear reduction in the shear forces was observed in the columns and beams. The moment around the beams and columns along the $\mathrm{z}$ axis was reduced after addition of the RC infill walls.
\end{abstract}

Keyword: RC infill walls; ARC3D software; RC frame; Experimental work 